\title{
Pengaruh Logoterapi Kelompok terhadap Kemampuan Memaknai Hidup pada Residen Napza
}

\author{
Sutejo \\ Jurusan Keperawatan Poltekkes Kemenkkes Yogyakarta \\ Jalan Tatabumi No. 3, Banyuraden, Gamping, Banyuraden, Sleman \\ Daerah Istimewa Yogyakarta 55293 \\ Email: decsuthe@yahoo.com
}

\begin{abstract}
Abstrak
Penyalaghgunaan NAPZA (Narkotika, Psikotropika dan Zat Adiktif lainnya) merupakan bentuk perilaku koping yang tidak efektif dalam menyelesaikan kondisi stress. Masalah psikologis yang berdampak terhadap krisis makna hidup antara lain harga diri rendah, kurangnya motivasi, merasa tidakberdaya, keputusasaan, bahkan resiko bunuh diri. Logoterapi kelompok merupakan psikoterapi yang dapat membantu individu membangkitkan optimisme dalam menghadapi masa depan apapun kendala yang dihadapi. Tujuan penelitian untuk mengetahui pengaruh logoterapi kelompok terhadap kemampuan memaknai hidup pada residen NAPZA. Jenis penelitian ini quasi experiment dengan desain pretest-posttest with control group design. Populasi dalam penelitian ini adalah residen NAPZA yang ada di Balai Rehabilitasi Sosial Pamardi Putra Yogyakarta Dinas Sosial Provinsi DIY. Sampel pada penelitian ini ditetapkan secara random sampling yang terdiri dari 22 responden kelompok intervensi dan 22 responden kelompok kontrol. Variabel bebas berupa pemberian logoterapi kelompok menggunakan teknik VAT (Value Awareness Technique). Variabel terikat berupa makna hidup. Instrumen atau alat ukur data yang digunakan adalah Meaning in Life Quesioner). Analisis data menggunakan analisis Wilcoxon Signed Rank Test pada taraf signifikan 5\% $(p=0,05)$. Hasil rerata sebelum diberikan logoterapi pada kelompok kontrol yaitu 13,32 dan sesudah yaitu 17,00 dengan nilai $p$-value $=0,00<0,05$. Rerata sebelum diberikan logoterapi pada kelompok intervensi yaitu 10,59 dan sesudah yaitu 10,55 dengan $p$-value =0,974>0,05. Hasil uji statistik didapatkan nilai $p$-value=0,005>0,05. Kesimpulan ada perbedaan yang signifikan antara makna hidup residen yang diberikan dengan yang tidak diberikan logoterapi kelompok.
\end{abstract}

Kata Kunci: logoterapi, makna hidup, residen NAPZA

\section{The Influence of Group Logoteraphy on Drug Users' Resident In Interpreting The Meaning of Life's Ability}

\begin{abstract}
Drug abuse is ineffective coping behavior in resolving stress conditions. There are several psychological problems affecting the meaning of life's crisis such as: low self-esteem, lack of motivation, feeling powerless, desperation, and suicide risk. Group Logotherapy is a psychotherapy which can assist to evoke optimism of a humankind in facing the future after all obstacles encountered. The purpose of this study was to investigate the influence of group logotherapy on the drug users' resident in interpreting the meaning of life's ability. This study method was a quasi-experiment pretest-posttest with control group design was conducted at Permadi Putra Social Rehabilitation Center of Yogyakarta. Random sampling method applied to select the samples. All 44 samples were recruited and divided into two groups for both experimental group (22 samples) and control group (22 samples). Group Logotherapy by using Value Awareness Technique (VAT) concerned as Independent variable and Life's Meaning categorized as dependent variable. The Meaning in Life's questionnaire was applied to this study. Wilcoxon Signed Rank Test was attempted to analyzed the data with $5 \%$ significant value $(p=0,05)$. Results showed that the average result value for both pretest and posttest on the control group is 13,32 and 17,00 with $(p$-value $=0.00<0.05)$. While the average result value for both pretest and posttest on the experimental group is 10,59 and 10,55 ( $p$-value $=0.974>0.05)$. In conclusion, the
\end{abstract}


statistical analysis was found significant different result between both control and experimental groups on the drug resident users about their life's meaning.

Keywords: logotherapy, life's meaning, drug user

Info Artikel:

Artikel dikirim pada 13 Februari 2017

Artikel diterima pada 24 Maret 2017

DOI : http://dx.doi.org/10.21927/jnki.2017.5(1).27-32

\section{PENDAHULUAN}

Setiap manusia di dunia dalam menjalani proses kehidupan pasti selalu menghadapi permasalahan yang menyebabkan stres. Stres bisa berasal dari faktor individu maupun lingkungan yang senantiasa akan mempengaruhi kemampuan didalam menghadapi stresor baik secara adaptif maupun maladaptif. Mekanisme koping maladaptif yang digunakan individu untuk lari dari permasalahan merupakan kondisi kegagalan dalam menyelesaikan stress. Penyalahgunaan NAPZA (Narkotika, Psikotropika dan Zat Adiktif lainnya) merupakan bentuk perilaku koping yang tidak efektif dalam menyelesaikan kondisi stress.

Hasil laporan United Nations Office on Drug and Crime (UNIDC) tahun 2013 menjelaskan bahwa pada tahun 2011 diperkirakan 167 sampai dengan 315 juta orang (3,6\%-6,9\% dari populasi penduduk dunia usia 16-54 tahun) menggunakan NAPZA minimal sekali dalam setahun. Hasil suvei nasional perkembangan penyalahgunaan NAPZA di Indonesia tahun 2015 jumlah penyalahgunaan NAPZA diproyeksikan \pm $2,8 \%$ atau setara dengan $\pm 5,1-5,6$ juta jiwa dari populasi penduduk Indonesia. Sedangkan prevalensi di Provinsi Daerah Istimewa Yogyakarta (DIY) tahun 2011 mencapai 2,8\% dari jumlah penduduk rentan atau sekitar 69.000 orang (1).

Dampak dari kecanduan NAPZA (drugs addiction) meliputi aspek fisik, mental, psikis dan sosial (2). Menurut Pasal 25 Undang-Undang Nomor 35 tahun 2009 tentang norkotika bahwa pecandu dan korban penyalahgunaan narkotika wajib menjalani rehabilitasi medis dan sosial. Surat edaran Mahkamah Agung (MA) Nomor 07 tahun 2009 tentang menempatkan pemakai NAPZA ke panti terapi rehabiltasi yang diperkuat oleh peraturan bersama tentang pelaksanaan rehabilitasi bagi pecandu dan korban penyalahgunaan narkotika oleh Ketua MA, Menteri Hukum dan Ham, Jaksa Agung, Kepala Kepolisian RI, Menteri Kesehatan, Menteri Sosial, Kepala BNN pada tanggal 11 Maret
2014 mengenai pentingnya rehabilitasi bagi pecandu dan korban penyalahgunaan narkotika dibandingkan hukuman penjara (3-5).

Proses rehabilitasi korban penyalahgunaan NAPZA dilakukan melalui dua tahapan yaitu rehabilitasi medis dan rehabilitasi sosial (1). Rehabilitasi sosial merupakan proses pemulihan secara terpadu meliputi aspek fisik mental dan sosial agar pecandu NAPZA dapat kembali melaksanakan fungsi sosial dan masyarakat (3). Masalah psikologis yang dialami oleh para pengguna NAPZA ketika mengikuti program rehabiltasi salah satunya adalah kondisi depresi seperti harga diri rendah, kurangnya motivasi, merasa tidak berdaya, keputusasaan bahkan beresiko melakukan bunuh diri.

Depresi sebagai dampak penyalahgunaan NAPZA dapat terjadi akibat kecaman keluarga, teman dan masyarakat atau kegagalan dalam mencoba berhenti memakai narkoba. Namun individu yang depresi tanpa ada riwayat penyalahgunaan NAPZA juga dapat menjadi pemakai karena mereka berpikir bahwa NAPZA dapat mengatasi dan melupakan masalah yang didihadapinya. Berbagai upaya kongkret yang dapat dilakukan yaitu menjalin kerja sama dengan pihak yang berwenang untuk melakukan penyuluhan tentang bahaya narkoba, atau mengadakan razia secara rutin (6).

Salah satu jenis psikoterapi yang dapat dilakukan untuk mengatasi masalah psikososial yang terjadi pada penyalahgunaan NAPZA yaitu melalui logoterapi kelompok. Logoterapi adalah salah satu terapi yang membangkitkan kognitif individu untuk dapat memahami potensi diri dan meningkatkan kemampuan dalam membuka situasi hidup sehingga hidup menjadi lebih bermakna (7). Logoterapi merupakan terapi yang bermanfaat untuk membantu seseorang untuk meningkatkan konsep diri khususnya harga diri. Hal tersebut diperoleh dari proses penerimaan diri secara kognitif, afektif dan perubahan perilaku yang adaptif (8). 
Logoterapi adalah psikoterapi yang dapat melihat individu secara jelas dan holistik meliputi gambaran diri, kepercayaan diri dan kemampuan individu dalam menangani stress (4). Penelitian mengenai logoterapi sudah banyak dilakukan untuk kondisi klien dengan penyakit terminal, kondisi penyakit kronik, berduka, depresi, Post Trauma Syndrome Distres (PTSD), ketergantungan alkohol, gangguan kepribadian, obsessive compulsive disorder dan phobia (9-11). Berdasarkan hal tersebut maka peneliti ingin mengetahui pengaruh logoterapi kelompok terhadap makna hidup sebagai dampak dari masalah psikososial pada residen NAPZA.

\section{BAHAN DAN METODE}

Jenis penelitian yang dilakukan adalah quasi experiment dengan rancangan pretest-posttest with control group design. Penelitian dilaksanakan di Balai Rehabilitasi Sosial Pamrdi Putra (BRSPP) Dinas Sosial Provinsi DIY dengan kriteria inklusi residen dalam kondisi tidak gaduh gelisah, bersedia menjadi responden dan tidak ada hambatan komunikasi. Sedangkan kriteria eksklusi dalam penelitian ini yaitu responden yang mengalami gangguan psikotik. Besar sampel berdasarkan rumus proporsi dengan harga proporsi di populasi $12 \%$, nilai kesalahan absolut $10 \%$ dan perkiraan proporsi drop out $10 \%$ didapatkan sampel 22 orang untuk kelompok intervensi dan 22 orang untuk kelompok kontrol yang diambil dengan teknik random sampling.

Pemberian logoterapi dalam penelitian ini terdiri dari empat sesi yaitu sesi satu mengidentifikasi masalah, sesi dua stimulasi imaginasi yang kreatif, sesi 3 menghadirkan situasi yang memberi makna dan sesi 4 makna hidup. Pengumpulan data menggunakan kuesioner kemampuan makna hidup yang diadopsi dari Meaning in Life Quesione, yang diukur dengan skala data interval dengan jumlah pernyataan sebanyak 10 item $(12,13)$. Pemberian logoterapi menggunakan teknik VAT (Value Awareness Technique) untuk meningkatkan makna hidup residen NAPZA (11). Perlakuan pada kelompok intervensi, setelah dilakukan pre test dilakukan logoterapi kelompok sebanyak empat sesi. Setelah intervensi selesai dilakukan post test untuk menilai makna hidup setelah diberikan logoterapi kelompok. Pada kelompok kontrol pelaksanaan pretest dan post test dilakukan bersamaan dengan kelompok intervensi. Analisa data dengan menggunakan Wilcoxon Signed Rank Test pada taraf signifikan $5 \%(p=0,05)$.

\section{HASIL DAN BAHASAN}

Rerata usia residen NAPZA di Balai Rehabilitasi Sosial Pamardi Putra Yogyakarta yaitu 25,86 tahun dengan rentang 17-34 tahun. Tugas perkembangan pada masa ini individu menghadapi tugas perkembangan pembentukan relasi yang akrab dengan orang lain. Keakraban sebagai penemuan diri sendiri, pada masa ini individu dihadapkan pada tugas perkembangan pembentukan relasi intim dengan orang lain (14). Saat anak muda membentuk persahabatan yang sehat dan relasi akrab yang intim dengan orang lain, keintiman akan akan dicapai, namun jika tidak, isolasi akan terjadi. Namun sayangnya, salah satu bentuk keintiman atau persahabatan yang kerap kali dilakukan adalah melakukan pemakaian zat-zat terlarang (15).

Mayoritas pendidikan Reziden NAPZA di Balai Rehabilitasi Sosial Pamardi Putra Yogyakarta adalah lulusan SMA. Pendidikan memberikan peranan penting dalam pencegahan penyalahgunaan NAPZA. Sebagian besar penyalahguna lulusan SMA menggunakan NAPZA karena motif ingin tahu, adanya kesempatan dan sarana prasarana, ketidakstabilan emosi dan lemahnya mental, dan belum siapnya diri mereka menghadapi setiap persaingan dengan individu lain (16).

Hasil penelitian kemampuan memaknai hidup pada pada kelompok intervensi dan kontrol sebelum diberikan terapi bercerita dilihat pada Tabel 1 dan Tabel 2.

Tabel 1. Makna Hidup Residen NAPZA Sebelum dan Sesudah Diberikan Logoterapi pada Kelompok Kontrol di BRSPP Dinas Sosial Provinsi DIY September $2016(n=22)$

\begin{tabular}{ccccc}
\hline Kelompok & \multicolumn{2}{c}{ Mean } & \multirow{2}{*}{ z } & p-value \\
\cline { 2 - 3 } Kontrol & Sebelum & Sesudah & & \\
\hline Makna Hidup & 10,59 & 10,55 & $-0,032$ & 0,974 \\
\hline
\end{tabular}

Berdasarkan Tabel 1 didapatkan data bahwa rerata sebelum diberikan logoterapi pada kelompok kontrol yaitu 10,59 dan sesudah yaitu 10,55. Tidak ada perbedaan yang signifikan sebelum dan sesudah pada kelompok kontrol dengan $p$-value $=0,974>0,05$.

Hasil penelitian menunjukkan bahwa tidak ada perbedaan rata-rata skor makna hidup sebelum dan sesudah pada kelompok kontrol. Kekecewaan dan kehampaan eksistensial yang dialami oleh residen NAPZA berawal dari gagalnya menemukan makna hidup dan memenuhi hasrat untuk hidup 
bermakna menimbulkan perasaan tidak nyaman dan ketidakpastian yang cukup intensif dan mengancam harga dirinya. Makna hidup residen NAPZA ketika masih dalam tahap penyalahgunaan yaitu mereka merasa dirinya sudah tidak berarti dan kehidupannya sudah tidak jelas. Setelah residen lepas dari NAPZA, mereka cenderung lebih dekat dengan Tuhan (religius) dan juga merasa bahwa Tuhan telah mengabulkan semua doa dan keinginannya.

Penggunaan narkoba secara terus menerus akan menyebabkan kecanduan (addiction). Kecanduan pada pengguna narkoba adalah suatu proses yang berkesinambungan, biasanya dimulai dari rasa ingin tahu pada narkoba sampai pada tahap kompulsif, dimana kebutuhan untuk mengkonsumsi narkoba menjadi kebutuhan psikologis dan fisiologis bagi penggunanya (17). Konsep dari pengguna atau pecandu narkoba adalah, pola maladaptive dari pemakaian narkoba yang secara klinis membuat individu menjadi stress dan mempunyai keterbatasanketerbatasan dalam memenuhi perannya sebagai individu, rentan terhadap bahaya, melanggar UU, dan menyebabkan munculnya konflik sosial maupun interpersonal. Bagi orang yang telah lama menggunakan narkoba, biasanya akan timbul rasa jenuh dan memiliki keinginan untuk berhenti. Mantan pecandu akan mulai berhenti dari kebiasaan mengkonsumsi narkoba ketika mereka merasa malu dan bersalah kepada keluarga maupun lingkungan karena telah mengetahui kebiasaan buruknya. Pada saat itulah biasanya pengguna narkoba akan menyadari konsekuensi negatif yang ditimbulkan oleh narkoba, kemudian masuk ke panti rehabilitasi.

Tabel 2. Makna Hidup Residen NAPZA Sebelum dan Sesudah Diberikan Logoterapi pada Kelompok Intervensi di BRSPP Dinas Sosial Provinsi DIY September $2016(n=22)$

\begin{tabular}{ccccc}
\hline Kelompok & \multicolumn{2}{c}{ Mean } & \multirow{2}{*}{ z } & p-value \\
\cline { 2 - 4 } Intervensi & Sebelum & Sesudah & & \\
\hline Makna Hidup & 13,32 & 17,00 & $-4,133$ & 0,00 \\
\hline
\end{tabular}

Berdasarkan Tabel 2 didapatkan data bahwa rerata sebelum diberikan logoterapi pada kelompok kontrol yaitu 13,32 dan sesudah yaitu 17,00. Ada perbedaan yang signifikan sebelum dan sesudah pada kelompok intervensi dengan nilai $p$-value $=0,00<0,05$.

Hasil penelian menunjukkan bahawa ada peningkatan rata-rata skor makna hidup pada kelompok yang diberikan logoterapi. Menurut
Undang-Undang No.35 Tahun 2009 tentang narkotika pasal 54 dan 55 rehabilitasi Medis adalah suatu proses kegiatan pengobatan secara terpadu untuk membebaskan pecandu dari ketergantungan narkotika. Rehabilitasi medis pecandu narkotika dapat dilakukan di rumah sakit yang ditunjuk oleh Menteri Kesehatan, yaitu rumah sakit yang diselenggarakan baik oleh pemerintah, maupun oleh masyarakat. Menurut rehabilitasi medik ini dimaksudkan agar mantan penyalahguna NAPZA benar-benar sehat secara fisik. Rehabilitasi psikiatrik ini dimaksudkan agar peserta rehabilitasi yang semula bersikap dan bertindak antisosial dapat dihilangkan, sehingga mereka dapat bersosialisasi dengan baik dengan sesama rekannya maupun personil yang membimbing atau mengasuhnya (2).

Penanganan pecandu narkoba di Indonesia dilaksanakan menggunakan beberapa metode terapi dan rehabilitasi yaitu: Cold turkey artinya seorang pecandu langsung menghentikan dengan cara mengisolasi dalam masa putus obat tanpa memberikan obat-obatan. Setelah gejala putus obat hilang, pecandu dikeluarkan dan diikutsertakan dalam sesi konseling (rehabilitasi nonmedis). Metode ini banyak digunakan oleh beberapa panti rehabilitasi dengan pendekatan keagamaan dalam fase detoksifikasinya, kemudian terapi substitusi opioda, terapi ini hanya digunakan untuk pasienpasien ketergantungan heroin (opioda). Untuk pengguna opioda hard core addict (pengguna opioda yang telah bertahun-tahun menggunakan opioda suntikan), pecandu biasanya mengalami kekambuhan kronis sehingga perlu berulang kali menjalani terapi ketergantungan $(4,5)$.

Hasil penelitian menunjukkan menunjukkan bahwa teknik logoterapi didasarkan atas prinsip bahwa hidup manusia memiliki makna yang penting yang harus dicapai dalam hidup dan setiap individu memiliki kebebasan dalam menemukan sendiri maknanya serta makna hidup dapat ditemukan dalam kehidupan individu itu sendiri dalam kondisi apapun dan harus disertai dengan keyakinan (6). Kemampuan memaknai hidup ini merupakan hasil akhir dari kemampuan residen NAPZA dalam menyadari dan melihat kondisi diri, dengan menyadari kondisi yang dirasakan, memiliki harapan atas kondisi tersebut, untuk melakukan sesuatu yang dapat membuat mereka menyadari secara penuh tanggung jawabnya, pilihan pada dirinya untuk menjadi bertanggung jawab dan pada akhirnya residen akan menemukan makna dari kehidupannya. 


\section{SIMPULAN DAN SARAN}

Sebagian besar residen NAPZA di BRSPP Dinas Sosial Provinsi DIY berjenis kelamin lakilaki, usia dewasa muda dan berpendidikan SMA pada residen NAPZA. Tidak ada perbedaan yang signifikan makna hidup residen NAPZA sebelum dan sesudah diberikan logoterapi pada kelompok kontrol. Ada perbedaan yang signifikan makna hidup residen NAPZA sebelum dan sesudah diberikan logoterapi pada kelompok intervensi. Ada perbedaan makna hidup antara kelompok yang diberikan dan tidak diberikan logoterapi pada residen NAPZA di BRSPP Dinas Sosial Provinsi DIY.

Makna hidup yang sudah dimiliki oleh residen NAPZA diharapkan dapat ditingkatkan karena merupakan aspek yang penting dalam membantu mengembangkan sikap optimisme. Petugas kesehatan diharapkan dapat menerapkan logoterapi kelompok sebagai salah satu pendekatan psikoterapi dalam membantu residen NAPZA untuk dapat meningkatkan kesehatan mental selama menjalani proses rehabilitasi. Perlu disusun standar operasional prosedur dalam pelaksanaan logoterapi kelompok bagi residen NAPZA sebagai program psikoterapi yang diberikan selama mengikuti rehabilitasi.

\section{RUJUKAN}

1. Badan Narkotika Nasional Daerah Istimewa Yogyakarta. Rekap Ungkap Kasus Narkoba di DIY 2008-2014 [Internet]. [cited 2016 Jan 10]. Available from: http://bnnp-diy.com/bnnyogyakarta.

2. Hawari D. IImu kedokteran jiwa dan kesehatan jiwa. 3rd ed. Yogyakarta: Dana Bhakti Prima Yasa; 2004.

3. Badan Narkotika Nasional Republik Indonesia. Undang-Undang Republik Indonesi No. 35 tahun 2009 tentang Narkotika dalam Lampiran I UU R.I. No. 35 Tahun 2009 [Internet]. 2009 [cited 2016 Apr 20]. Available from: http://www.bnn.go.id/

4. Badan Narkotika Nasional Republik Indonesia. Survey Nasional Perkembangan Penyalahgunaan Narkoba Tahun Anggaran 2014 [Internet]. 2015 [cited 2016 Sep 1]. Available from: http://www. bnn.go.id/

5. Badan Narkotika Nasional Republik Indonesia. Rehabilitasi Mantan Pecandu Narkoba [Internet].
2014 [cited 2016 Feb 1]. Available from: http:// www.bnn.go.id/

6. Badan Narkotika Nasional Republik Indonesia. Dampak Langsung dan Tidak Langsung Penyalahgunaan Narkoba [Internet]. 2014 [cited 2017 Feb 8]. Available from: http://www.bnn. go.id/

7. Hergenhahn B, Henley T. An Introduction to The History of Psychology. 7th ed. Belmont, CA: Wadsworth Publishing; 2013.

8. Maryatun S, Hamid AYS, Mustikasari. Logoterapi meningkatkan harga diri narapidana perempuan pengguna narkotika. J Keperawatan Indones. 2014;17(2).

9. Bastaman H. Logoterapi: Psikologi untuk Menemukan Makna Hidup dan Memilih Hidup Bermakna. 1st ed. Jakarta: Raja Grafindo Persada; 2007.

10. Sutejo, Keliat B, Hastono S, Daulima N. Pengaruh Logoterapi Kelompok Terhadap Ansietas pada Penduduk Pasca Gempa di Kabupaten Klaten Propinsi Jawa Tengah. J Keperawatan Indones. 2011;14(2).

11. Wahyuni S, Keliat B, Budihartono. Pengaruh Logoterapi Terhadap Peningkatan Kemampuan Kognitif dan Perilaku pada Lansia Dengan Harga Diri Rendah di Panti Wreda Pekanbaru Riau. J Ners Indones. 2011;1(1).

12. Hutzell RR, EggertJerkins M, Hutzell R, Clinical Psychologistand Director I. The Use of A Logotherapy Technique In The Treatment of Multiple Personality Disorder. DISSOCIATION [Internet]. 1990 [cited 2016 Sep 11];3(2). Available from: https://scholarsbank.uoregon.edu/xmlui/ bitstream/handle/1794/1529/Diss_3_2_11_OCR_ rev.pdf? sequence $=4$.

13. Kang K-A, Im J-I, Kim H-S, Kim S-J, Song M-K, Sim S. The Effect of Logotherapy on the Suffering, Finding Meaning, and Spiritual Well-being of Adolescents with Terminal Cancer. J Korean Acad Child Heal Nurs [Internet]. 2009;15(2):136. Available from: http://e-chnr.org/journal/view. php?id=10.4094/jkachn.2009.15.2.136.

14. Saleh HD, Rokhmah D, Nafikadini I. Fenomena Penyalahgunaan NAPZA Di Kalangan Remaja Ditinjau Dari Teori Interaksionisme Simbolik Di Kabupaten Jember (The Phenomenon of Substance Abuse among Adolescents Based on Symbolic Interactionism Theory in Jember Regency). Pustaka Kesehat. 2014;2(3):468-75. 
15. Hotpascaman S. Hubungan antara Perilaku Konsumtif Dengan Konformitas pada Remaja. Universitas Sumatera Utara; 2010.

16. Huda A. Konseling dalam Proses Rehabilitasi Korban Penyalahgunaan NAPZA di Panti Sosial
Pamardi Putra Yogyakarta [Internet]. UIN Sunan Kalijaga; 2010. Available from: http://digilib.uin-suka. ac.id/6085/

17. Stuart G, Laraia M. Principles and Practice of Psychiatric Nursing. 8th ed. ST Louis: Mosby; 2005. 